\title{
John T. Edge, Elizabeth Engelhardt \& Ted Ownby (eds.), The Larder: Food Studies Methods from the American South, Athens: The University of Georgia Press, 2013.
}

\author{
Recensão de Maria Teresa Castilho \\ CETAPS/ Universidade do Porto
}

The Larder: Food Studies Methods from the American South, publicado por John T. Edge, Elizabeth Sanders Delwiche Engelhardt, Ted Ownby em 2013, reúne quinze ensaios e uma conclusão intitulada "Go Forth with Method", que, ao ser considerada só por si, acaba, sem dúvida, por funcionar também como um dos ensaios que integra esta esclarecedora antologia. Com efeito, The Larder oferece um notório e pertinente contributo para o entendimento e problematização do(s) caminho(s) e dos métodos que os Estudos sobre a Alimentação seguem hoje no Sul como região no contexto cultural dos Estados Unidos, ao mesmo tempo que sublinha interseções entre áreas e disciplinas que de algum modo nos ocupam enquanto estudiosos desta região cultural.

John T. Edge é diretor da Southern Foodways Alliance Studies in Culture, People, and Place, sediada na Universidade do Mississippi e por muitos considerada uma das mais envolventes associações de estudos sobre alimentação. Por outro lado, John Edge é também autor de uma considerável bibliografia na área dos Estudos sobre a Alimentação onde se inclui o volume da The New Encyclopedia of Southern Culture sobre alimentação no "Sul"; Elizabeth Engelhardt é especialista em Estudos Sulistas e está ligada à universidade de 
North Carolina e Ted Ownby é professor de História e Estudos do Sul na Universidade do Mississippi, onde é diretor do Centro para o Estudo da Cultura do Sul.

Em The Larder dispomos de ensaios com incidências diversas e da responsabilidade de nomes soantes e considerados na área dos Estudos sobre a Alimentação no Sul, como é o caso do de Psyche Williams-Forson (capítulo 13), ou de estudiosos mais recentes, como acontece com Rien Fertel (Capítulo 1). Porém, quer sendo da autoria de uns ou de outros, é notório que esses ensaios se reúnem em torno do objetivo comum de procurar acentuar e problematizar uma diversidade nos hábitos alimentares da região, o que, de algum modo, lança o debate sobre uma complexidade cultural dentro da própria cultura sulista, hoje mais do que nunca em mudança. Ao mesmo tempo, e numa espécie de estratégia de diálogo entre disciplinas e áreas, The Larder problematiza as alterações que o mundo americano acabou por trazer à dieta "sulista", pervertendo-a por vezes de algum modo. No seu conjunto, estes textos, que se organizam em Cinco Partes ("Cookbooks and Ingredients"; "People and Communities"; "Spaces and Technologies"; "Material Cultures"; "On Authenticity"), apresentando todas elas uma pequena introdução que antecede o agrupamento temático dos ensaios de cada uma dessas partes em capítulos, constituem um esclarecedor e pertinente indicador de como são encarados e como evoluem os Estudos sobre a Alimentação no Sul. Acentuando as circunstâncias de género, raça e etnia, ao mesmo tempo que problematiza questões da identidade, The Larder: Food Studies Methods from the American South explora e dá conta não só do desenvolvimento e interesse que esta área de estudos tem tido no "Sul”, mas também como aí os Estudos sobre a Alimentação se cruzam com chamadas de atenção que buscam problematizações que conduzem a uma melhor compreensão das diferentes culturas que nessa região cultural americana coexistem, e/ou até se sobrepõe por vezes. Como Beth A. Latshaw deixa claro no capítulo 5 - "The Soul of the South: Race, Food, and Identity in the American South" -, se, como o sociólogo Larry J. Griffi observa, é certo que nenhuma outra região dos Estados Unidos tem sido tão estudada e analisada como o "Sul" também é igualmente inegável que a crença de que esta região cultural é de alguma forma qualitativamente"diferente" do resto da América tem levado hoje os estudiosos da área dos Estudos Sulistas a procurar e a ponderar o que significa ser 
"sulista" na América do século XXI. Num tempo em que o que significa ser "Sul" e ser "sulista" é cada vez mais ambíguo, uma vez que a identidade da região vai-se mostrando mais e mais fraturada e a forte industrialização e o poder corporativo tomam conta da sua vida e da sua paisagem, a celebração e a recuperação do que tradicionalmente foi a "dieta sulista" é, para os autores que se associam em The Larder, também um aspeto a defender e a ter em conta para sublinhar a diferença cultural dessa região.

Na sua introdução, Elizabeth Engelhardt chama a atenção para o facto de os editores de The Larder não só sublinharem com este volume o desenvolvimento dos Estudos sobre a Alimentação, mas igualmente acentuarem que, no "Sul”, os autores e intelectuais "sulistas", e até mesmos os que não estão diretamente ligados a esta área de estudos, se dedicam com entusiasmo e grande atenção ao envolvimento cultural que a alimentação e os hábitos alimentares oferecem nesta região. Procurando e afirmando métodos e metodologias que levam estes reconhecidos intelectuais e estudiosos a considerarem-se na primeira linha de contribuições para a disciplina dos Estudos sobre a Alimentação no contexto nacional americano, os Estudos Sulistas e os Estudos sobre a Alimentação fundem-se num contributo que problematiza hábitos alimentares, padrões de exclusão e abordagens sobre raça, classe e etnia.

Do ponto de vista dos autores presentes nesta antologia, os Estudos sobre a Alimentação não nos ajudam só dominante e exclusivamente a refletir sobre os alimentos que procuramos e ingerimos ou sobre os hábitos alimentares adotamos. Segundo estes estudiosos, o mérito desta disciplina, tal como se tem desenvolvido no "Sul", reside também no desnudar de métodos e de estratégias que utilizam os alimentos e as dietas alimentares como modos para examinar, compreender e problematizar uma cultura.

Ao concluir The Larder: Food Studies Methods from the American South, Ted Ownby sublinha que o seu ensaio não é escrito do ponto de vista de um estudioso dentro da área dos Estudos sobre a Alimentação, mas do de um historiador do "Sul" que tem assistido ao desenvolvimento, crescimento e interesse académico no que se prende com esta área na sua região. É desse ponto de vista que Ownby nos deixa com uma avaliação pertinente e muito meritória acerca da importância dos Estudos sobre a Alimentação, fazendo votos 
Maria Teresa Castilho

para que esta coletânea de textos seja um contributo (e inegavelmente ela o é) para deixar mais claro o grande potencial de abordagens interdisciplinares no estudo da (nossa) vida alimentar e cultural. 